\title{
Synthesis, Growth, Investigation of Structural, Spectral and Optical Properties of Solution Grown Dipotassium Fumarate Dihydrate Crystal
}

\author{
N.Kalaimani ${ }^{1}$, K.Ramya ${ }^{2}$, R.Aarthi ${ }^{3}$, C.Ramachandra Raja ${ }^{3 *}$ \\ ${ }^{1}$ Department of Physics, Thiru.Vi.Ka Government Arts College, Thiruvarur 610 003, Tamilnadu, India \\ ${ }^{2}$ Department of Physics, TUK Arts College, Thanjavur 613 002, Tamilnadu, India \\ ${ }^{3}$ Department of Physics, Government Arts College (Autonomous), Kumbakonam 612 002, Tamilnadu, India \\ "Corresponding Author: crraja@ rediffmail.com Tel.: 9976696277
}

Available online at: www.isroset.org

Received: 23/Sept/2018, Accepted: 19/Oct/2018, Online: 31/Oct/2018

\begin{abstract}
Single crystals of dipotassium fumarate dihydrate (DKFD) have been grown by slow solvent evaporation method. The structural characteristics of the grown crystals was studied from single crystal and powder X-ray diffraction analysis. The crystal system of the grown crystal was found to be monoclinic. The lower cut-off wavelength of DKFD was found at $300 \mathrm{~nm}$ and good transparency window was observed from 300 to $1100 \mathrm{~nm}$. The existence of various functional groups was established from FTIR and FT Raman spectroscopy. The study of the molecule is established using NMR spectroscopy. The thermal stability and decomposition behaviour of the grown crystal is analysed using TGA/DTA analyses. Third order nonlinear susceptibility $\chi^{3}$ of the crystal was measured at the wavelength of $532 \mathrm{~nm}$ by z-scan technique. The observed high value of $\chi^{3}$ is attributed to the hydrogen bond present in the structure of the crystal.
\end{abstract}

Keywords - Dipotassium fumarate dihydrate, Single crystal XRD, Powder XRD, NMR analysis, Z-Scan technique.

\section{INTRODUCTION}

The motive of the research is to synthesis a new compound in order to fulfil the requirements for the technological development in various fields. Organic crystals produce large nonlinear optical response, low UV cut off wavelength, but have poor mechanical and thermal stability. Inorganic crystals have high melting point, high mechanical strength but possess poor optical nonlinearity. The combination of organic and inorganic compounds that are easily grown from solution growth technique leads to find a material suitable for device applications. The semiorganic crystals are grown due to their stable physiochemical properties, that are essential for fabrication of devices and in applied research $[1,2,3]$. Semiorganic crystals are of great interest and found its applications in the field of optical computing, data storage, optical information processing and light emitting diodes [4,5]. Semiorganic materials with hydrogen bonding interactions between cations and anions possess large nonlinearity, low angular sensitivity, large polarizability, better transmittance in UV-Vis region, good mechanical and thermal stability [6-9]. Ionic salt materials provide an important and intense flexible approach for the material development that are used over a broad range of frequencies [10].

\section{RELATED WORK}

The structure of the title crystal was already reported [11]. In this work the semiorganic DKFD crystals were grown using low temperature solution growth method. The grown crystals were characterized using single crystal X-ray and powder Xray diffraction method, UV-Vis-NIR spectroscopy, FT-IR and FT-Raman spectroscopy, NMR spectroscopy, Thermal analysis and Z-Scan analysis.

\section{MATERIALS AND METHODS}

DKFD crystals was obtained from solvent evaporation technique by reacting potassium carbonate and fumaric acid in a molar ratio of 1:1. The weighed reactants were dissolved in deionised water and stirred continuously with magnetic stirrer for about 3hours, and then filtered using Whatman filter paper. The filtered solution was kept in a crystal growth vessel, and covered with polythene paper. Few holes were made in the polythene paper to achieve slow evaporation. After a period of 70 days colourless crystals were grown. Figure 1, shows the reaction scheme of DKFD crystal. 
<smiles>CC(C)(C)OC(=O)/C=C/C(=O)NCC(=O)/C=C/C(=O)O[Mg]</smiles>

Figure 1. Chemical reaction scheme of DKFD crystal

\section{RESUlTS AND DISCUSSION}

\subsection{Single crystal XRD analysis}

The lattice parameter of DKFD crystal was determined using NONIUS CAD4 single crystal X-ray diffractometer with $\operatorname{MoK} \alpha(\lambda=0.71069 \AA)$ radiation. The grown crystal belongs to centrosymmetric $\mathrm{P} 2_{1} / \mathrm{c}$ space group of monoclinic system. The observed lattice parameter matches with the previous reported values [11] and are given in Table 1

\subsection{Powder XRD analysis}

The crystallinity and structural property of DKFD crystal has been studied from powder X-ray diffraction technique. The crushed powder sample was analysed using Rich Seifert diffractometer with $\mathrm{CuK} \alpha \quad(\lambda=$ $1.54060 \AA$ ) radiation. The sample is scanned for $2 \theta$ values from $10^{\circ}$ to $90^{\circ}$ at a rate of $2 \%$ min. Figure 2, shows the Powder XRD pattern of the DKFD crystal. The diffraction pattern was indexed by Rietveld software package. The lattice parameter values were calculated by Rietveld unit cell software package and was matched with single crystal XRD data. The comparison of lattice parameter of single crystal and powder XRD analysis with reported values are given in Table 1.

Table 1. Lattice parameter of DKFD crystal

\begin{tabular}{|c|c|c|c|c|c|c|}
\hline XRD & $\begin{array}{c}a \\
\AA\end{array}$ & $\begin{array}{c}\mathrm{b} \\
\AA\end{array}$ & $\begin{array}{c}\mathrm{c} \\
\AA\end{array}$ & $\begin{array}{c}\alpha \\
\mathrm{deg}\end{array}$ & $\begin{array}{c}\beta \\
\mathrm{deg}\end{array}$ & $\begin{array}{c}\gamma \\
\mathrm{deg}\end{array}$ \\
\hline $\begin{array}{c}\text { Single } \\
\text { crystal }\end{array}$ & $6.338(2)$ & $7.2461(3)$ & $18.179(3)$ & 90 & $98.47(4)$ & 90 \\
\hline Powder & 6.336 & 7.2458 & 18.172 & 90 & 98.34 & 90 \\
\hline $\begin{array}{c}\text { Reported } \\
\text { Values } \\
{[10]}\end{array}$ & $6.35(4)$ & $7.27(2)$ & $18.22(8)$ & 90 & 98.2 & 90 \\
\hline
\end{tabular}

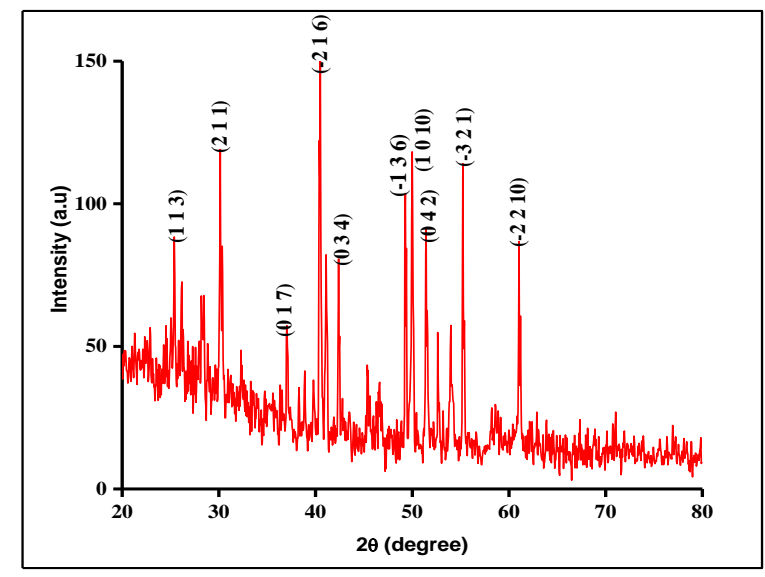

Figure 2. Powder X-ray diffraction pattern of DKFD crystal

\subsection{Optical transmission analysis}

The optical transparency range was observed from Perkin-Elmer UV-Vis-NIR spectrometer in the range 190 to $1100 \mathrm{~nm}$. The optical transmittance spectrum of DKFD crystal is shown in Figure 3. From the spectrum it is observed that, the lower cut-off wavelength lies at $300 \mathrm{~nm}$. The crystal has wide optical transmission from 300 to 1100 $\mathrm{nm}$. There was no further absorption of the crystal in UV, Vis, and near IR regions. This reveals that the DKFD crystal have good transparency and can be used for optoelectronic applications and also to produce frequency tripling of Nd:YAG laser fundamental wavelength $1064 \mathrm{~nm}$.

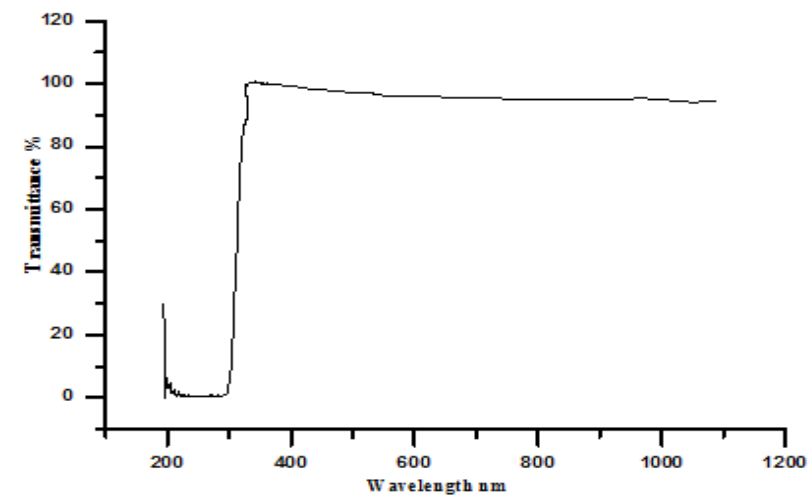

Figure 3. UV-Vis-NIR spectrum of DKFD crystal

\subsection{FTIR and FT Raman spectral analyses}

Fourier Transform infrared spectrum was recorded by the $\mathrm{KBr}$ pellet technique using a SPECTROMRXI FTIR spectrometer and FT Raman spectrum was recorded using BRUKER RFS 27 spectrometer to confirm the functional groups. The FTIR and FT Raman spectra of DKFD crystal are given in Figures 4 and 5 respectively. The vibrational frequencies and their corresponding assignments are given in Table 2. The absorption band in the higher wavenumber region at $3429 \mathrm{~cm}^{-1}$ is due to the $\mathrm{OH}$ stretching vibration. There was no absorption band found in IR and Raman spectra between 2900 and $1700 \mathrm{~cm}^{-1}$, and it was due to the 
metal cation $\mathrm{K}^{+}$, which replaces the position of hydrogen of carboxylate group, thus forming a bond between metal cation and carboxylate anion $\left(\mathrm{K}^{+}{ }^{-} \mathrm{OOC}\right)[12,13]$. The band observed at $1563 \mathrm{~cm}^{-1}$ and $1398 \mathrm{~cm}^{-1}$ in IR spectrum are attributed to the asymmetric and symmetric vibration of carboxylate group [14]. The difference between two wavenumbers $\Delta \mathrm{V}=165 \mathrm{~cm}^{-1}$ (asymmetric and symmetric vibration of $\mathrm{COO}^{-}$group) indicates the bridging mode of carboxylate groups with metal cation [15]. Thus, when $\Delta \mathrm{V}$ is below $200 \mathrm{~cm}^{-1}$, both carboxylate group of fumaric acid binds the metal cation $\left(\mathrm{K}^{+}\right)$forming bidentate bond [16]. The presence of band at $1222 \mathrm{~cm}^{-1}$ and $983 \mathrm{~cm}^{-1}$ in IR and $1269 \mathrm{~cm}^{-1}$ and $977 \mathrm{~cm}^{-1}$ in Raman spectra may be due to the asymmetric and symmetric stretching of $\mathrm{C}-\mathrm{C}$ vibration. The peak at $744 \mathrm{~cm}^{-1}$ in IR and $776 \mathrm{~cm}^{-1}$ in Raman were assigned to wagging of $\mathrm{C}-\mathrm{H}$ group.

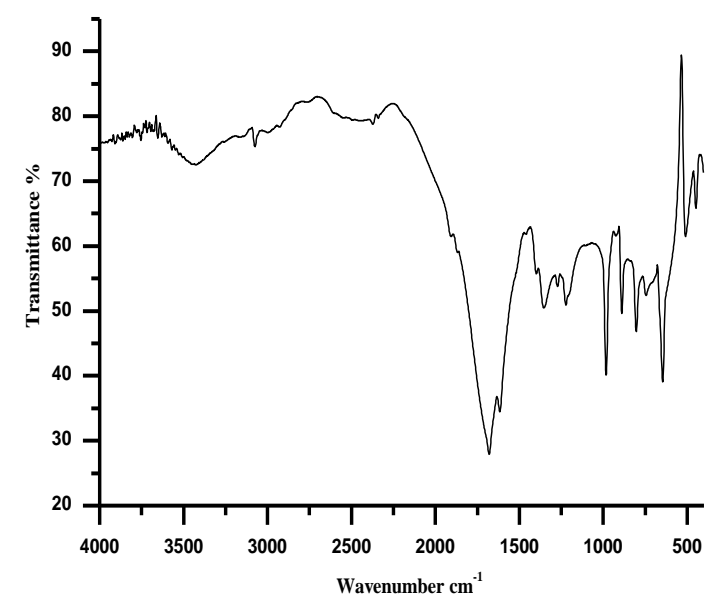

Figure 4. FTIR spectrum of DKFD crystal

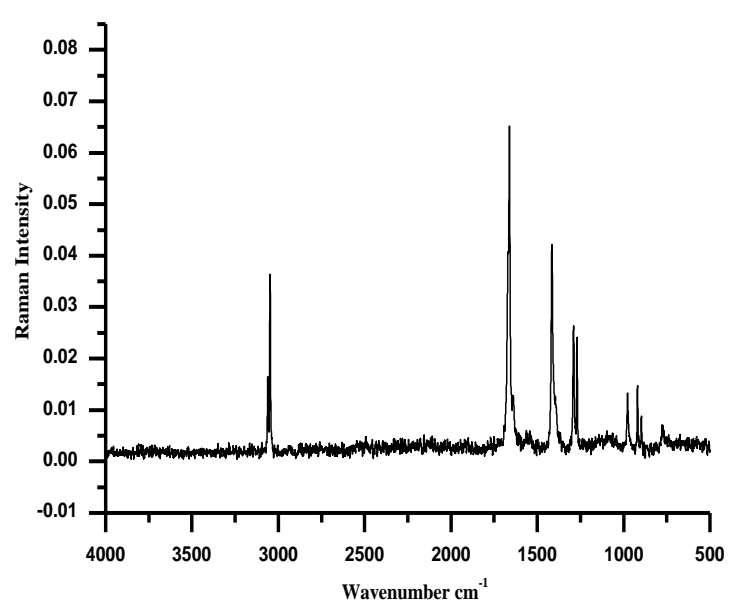

Figure 5. FT Raman spectrum of DKFD crystal
Table 2. Observed vibrational wavenumbers and their assignments

\begin{tabular}{|c|c|c|}
\hline \multicolumn{2}{|c|}{ Wavenumber $\mathrm{cm}^{-1}$} & \multirow{2}{*}{ Assignments } \\
\hline FTIR & FT Raman & OH stretching \\
\hline 3429 & 3374 & CH stretching \\
\hline 3074 & 3060 & COO $^{-}$asymmetric stretching \\
\hline 1563 & 1542 & COO $^{-}$symmetric stretching \\
\hline 1398 & 1415 & C-C asymmetric stretching \\
\hline 1222 & 1269 & C-C symmetric stretching \\
\hline 983 & 977 & C-O bending \\
\hline 889 & 897 & C=C stretching \\
\hline 867 & 876 & C-H wagging \\
\hline 744 & 776 & COO \\
\hline 646 & 674 & bending \\
\hline
\end{tabular}

\section{5. ${ }^{1} \mathrm{H}$ and ${ }^{13} \mathrm{C}$ NMR analysis}

The ${ }^{1} \mathrm{H}$ NMR and ${ }^{13} \mathrm{C}$ NMR spectra were recorded using $\mathrm{D}_{2} \mathrm{O}$ as solvent at room temperature employing BRUKER instrument operated at $400 \mathrm{MHz}$ for ${ }^{1} \mathrm{H}$ NMR and $100.6 \mathrm{MHz}$ for ${ }^{13} \mathrm{C} \mathrm{NMR}$ for the confirmation of molecular structure. The ${ }^{1} \mathrm{H}$ NMR spectrum for the DKFD crystal is given in Figure 6. The ${ }^{1} \mathrm{H}$ NMR peak value for fumaric acid and the DKFD crystal are given in the Table 3. The $\mathrm{D}_{2} \mathrm{O}$ solvent peak is observed at $\delta=4.692 \mathrm{ppm}$. The chemical shift of $\mathrm{CH}$ proton of fumaric acid in DKFD crystal appeared as a singlet at $\delta=6.52 \mathrm{ppm}$. On comparing this peak value with the corresponding protons of the parent fumaric acid $(\delta$ $=6.647 \mathrm{ppm}$ ), the values are shifted towards the upfield. Moreover the disappearance of the signal for the acid proton in NMR of the DKFD crystal indicated that the acid proton ($\mathrm{COOH})$ of the fumaric acid involved in bond formation with the potassium. The shift in value of $\mathrm{CH}$ proton and the disappearance of peak for acid proton indicates the intermolecular association between potassium and fumaric acid with the result in formation of crystal.

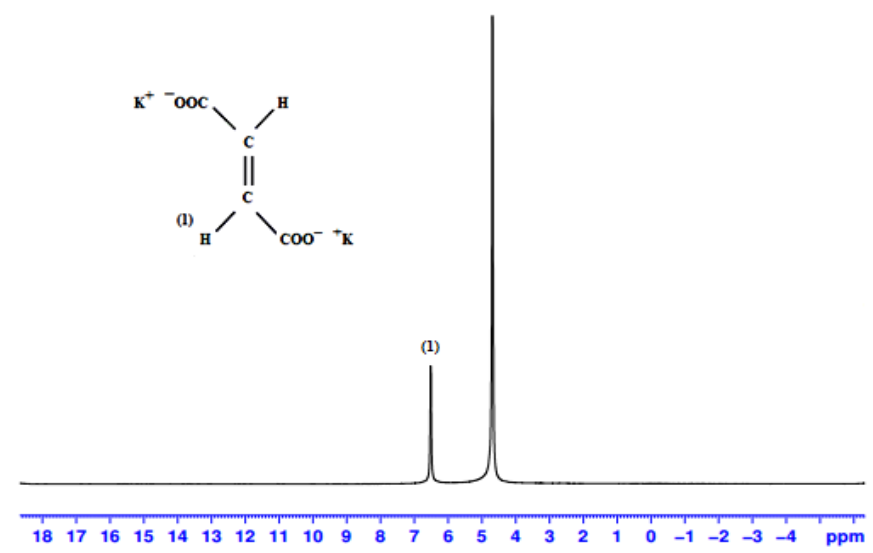

Figure 6. ${ }^{1} \mathrm{H}$ NMR spectrum of DKFD crystal 
Table 3. Chemical shifts in ${ }^{1} \mathrm{H}$ and ${ }^{13} \mathrm{C}$ NMR spectra of DKFD crystal

\begin{tabular}{|c|c|c|c|}
\hline \multicolumn{4}{|c|}{ Chemical shift $\delta(\mathrm{ppm})$} \\
\hline Spectra & $\begin{array}{c}\text { dipotassium } \\
\text { fumarate } \\
\text { dihydrate } \\
\text { crystal }\end{array}$ & $\begin{array}{c}\text { Fumaric } \\
\text { acid }\end{array}$ & $\begin{array}{c}\text { Group } \\
\text { Identification }\end{array}$ \\
\hline $\begin{array}{c}{ }^{1} \mathrm{H} \\
\mathrm{NMR}\end{array}$ & 6.52 & 6.647 & $\mathrm{CH}$ \\
\cline { 2 - 4 } & 4.692 & - & $\mathrm{D}_{2} \mathrm{O}$ \\
\hline${ }^{13} \mathrm{C}$ & 171.15 & 177.23 & $\mathrm{COOH}$ \\
\cline { 2 - 4 } $\mathrm{NMR}$ & 133.73 & 137.95 & $\mathrm{CH}$ \\
\hline
\end{tabular}

The ${ }^{13} \mathrm{C}$ NMR chemical shift for fumaric acid and the DKFD crystal are given in the Table 3 . Figure 7 , shows the ${ }^{13} \mathrm{C}$ NMR spectrum of DKFD crystal. The ${ }^{13} \mathrm{C}$ NMR spectrum exhibit two signals with respect to two carbon atoms due to different chemical environment. The peaks appearing at $\delta=$ $171.15 \mathrm{ppm}$ and $\delta=133.73 \mathrm{ppm}$ corresponds to the carbonyl carbon $(-\mathrm{CO}-)$ and methylidene carbon $(-\mathrm{CH}=)$ of DKFD crystal. On comparing the peak value with the parent fumaric acid (Table 3), the values are shifted towards the upfield. This shift is due to the formation of bond between potassium and fumaric acid and confirms the formation of DKFD crystal.

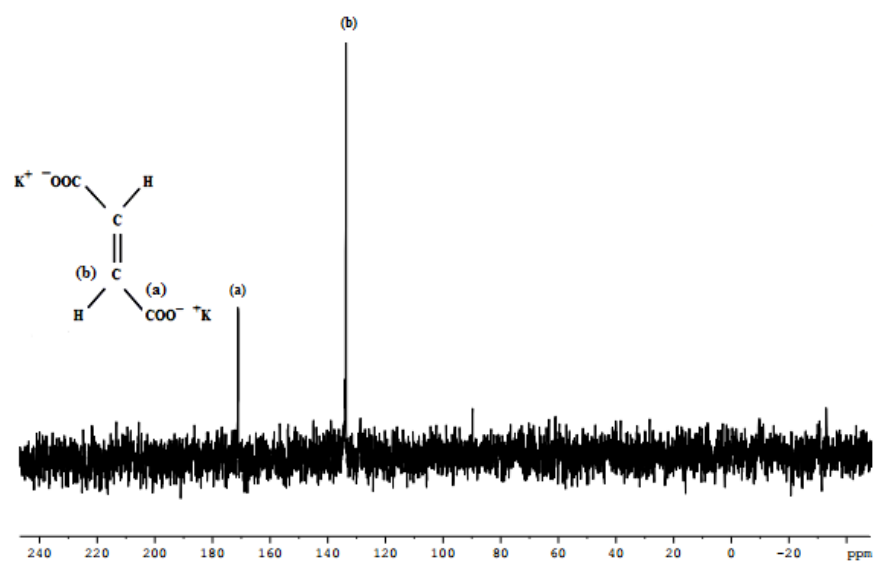

Figure $7 .{ }^{13} \mathrm{C}$ NMR spectrum of DKFD crystal

\subsection{Thermal studies}

The thermal analysis have been carried out using the instrument NETZSCH SDT Q600 V 8.3 build 101 in nitrogen atmosphere at a heating rate of $20^{\circ} \mathrm{C} / \mathrm{min}$ in the temperature $30-500^{\circ} \mathrm{C}$. The TG/DTA curves are shown in Figure 8 . The title compound starts to lose the two molecules of water of crystallization in the temperature range $75^{\circ} \mathrm{C}$ to $104^{\circ} \mathrm{C}$. The endothermic peak observed near $80^{\circ} \mathrm{C}$ may correspond to the release of water molecules of crystallisation. From the TGA curve the weight loss (of about $65 \%$ ) near $188^{\circ} \mathrm{C}$ was due to the decomposition of the crystal, which was reflected as an endothermic peak in DTA at $189^{\circ} \mathrm{C}$. The exothermic peaks above $350^{\circ} \mathrm{C}$ indicates the further decomposition of the compound. The crystal is stable upto $75^{\circ} \mathrm{C}$.

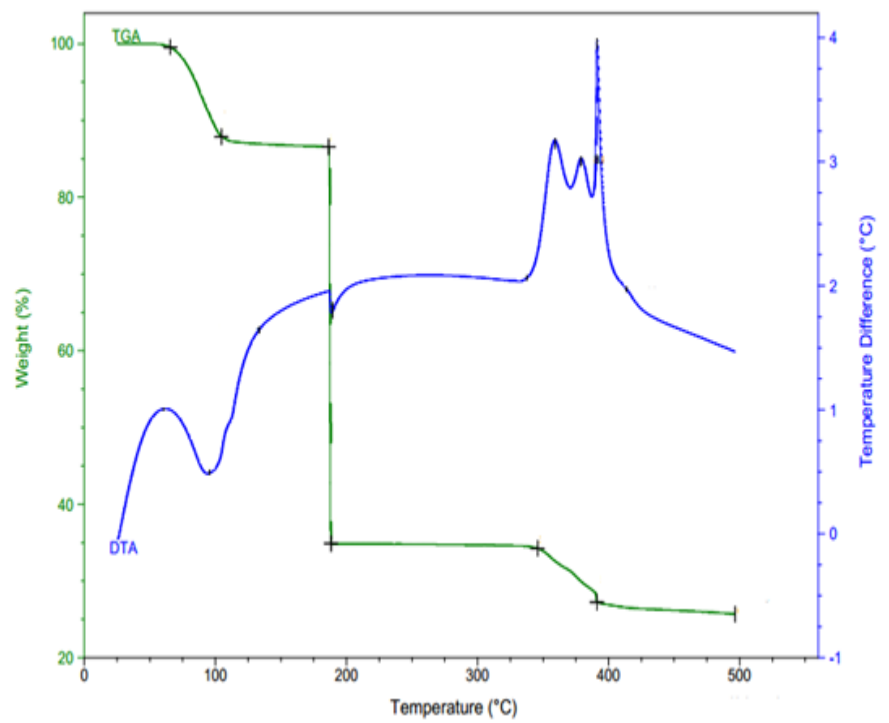

Figure 8. TG/DTA curve of DKFD crystal

\subsection{Third order NLO properties}

The third order nonlinear optical properties of were determined from z-scan analysis. The z-scan technique employs Nd:YAG laser of intensity $5 \mathrm{~mW}(\lambda=532 \mathrm{~nm})$, focussed by a lens of $3.5 \mathrm{~cm}$ focal length in order to measure the optical nonlinearity such as nonlinear refractive index $\left(\mathrm{n}_{2}\right)$, absorption co-efficient $(\beta)$ and third order nonlinear optical susceptibility $\left(\chi^{3}\right)$. The optical nonlinear parameters were determined from using standard formulas [17-20] and the values are given in Table 4 . The closed and open aperture curves from z-scan measurement are given in Figures 9 and 10 respectively. In the closed aperture curve (Figure 9), the pre focal peak is followed by a post focal valley which indicates that the nonlinear refraction $\left(\mathrm{n}_{2}\right)$ is negative for the crystal DKFD. Thus, the peak to valley configuration shows the self defocusing effect of the crystal. From the open aperture curve of dipotassium fumarate dihydrate crystal was shown in Figure 10, and it was concluded that the crystal exhibit saturable absorption property due to an increase in transmittance near the focus $(\mathrm{z}=0)$. The third order susceptibility of the DKFD crystal is high due to the presence of hydrogen bond present in the structure of the crystal[10]. Table 5 shows the $\chi^{3}$ values of some reported crystals. 


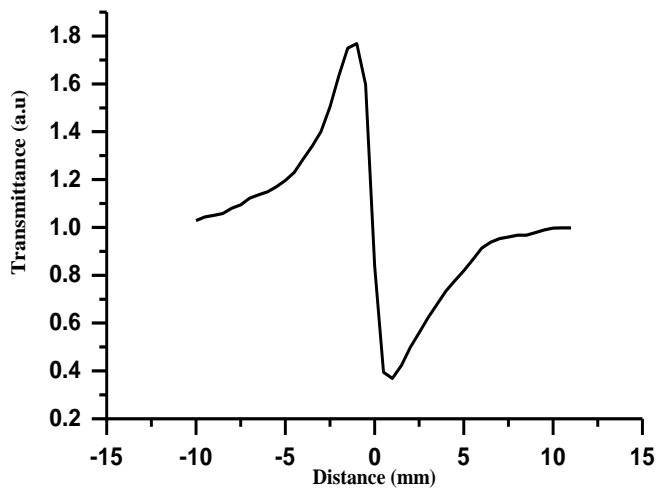

Figure 9. Closed aperture curve of DKFD crystal

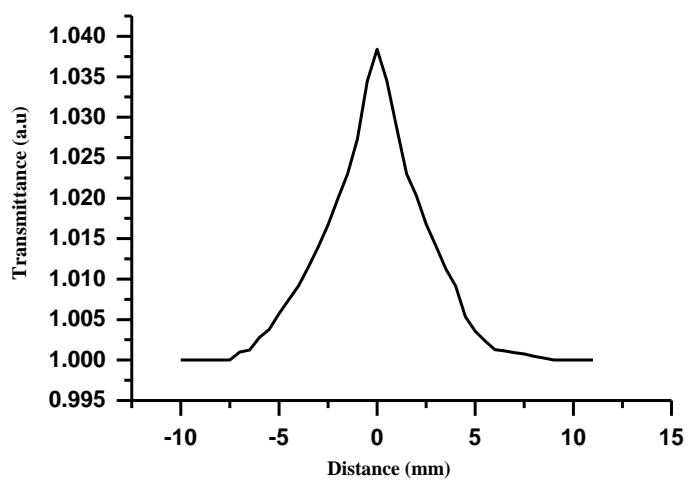

Figure 10. Open aperture curve of DKFD crystal

Table 4. Third order nonlinear optical parameters of DKFD dihydrate crystal

\begin{tabular}{|c|c|}
\hline Parameters & Values \\
\hline Nonlinear refractive index $\left(\mathrm{n}_{2}\right)$ & $-7.8 \times 10^{-8} \mathrm{~cm}^{2} / \mathrm{W}$ \\
\hline Nonlinear absorption co-efficient $(\beta)$ & $0.03 \times 10^{-4} \mathrm{~cm} / \mathrm{W}$ \\
\hline Real part of susceptibility $\left(\operatorname{Re} \chi^{3}\right)$ & $5.84 \times 10^{-6} \mathrm{esu}$ \\
\hline Imaginary part of susceptibility $(\mathrm{Im}$ & $0.19 \times 10^{-6} \mathrm{esu}$ \\
$\left.\chi^{3}\right)$ & \\
\hline Third order susceptibility $\left(\chi^{3}\right)$ & $5.85 \times 10^{-6} \mathrm{esu}$ \\
\hline
\end{tabular}

Table 5. $\left(\chi^{3}\right)$ values of DKFD with some third order nonlinear optical crystal

\begin{tabular}{|c|c|c|}
\hline $\begin{array}{c}\text { Crystal } \\
\text { name }\end{array}$ & $\begin{array}{c}\text { Third order susceptibility } \\
\left(\chi^{3}\right) \text { esu }\end{array}$ & References \\
\hline $\mathrm{DKFD}$ & $5.85 \times 10^{-6}$ & Present work \\
\hline $\mathrm{LiRbB}_{4} \mathrm{O}_{7}$ & $2.719 \times 10^{-7}$ & {$[21]$} \\
\hline $\mathrm{BCBA}$ & $4.853 \times 10^{-7}$ & {$[22]$} \\
\hline
\end{tabular}

\begin{tabular}{|c|c|c|}
\hline $4 \mathrm{BPTS}$ & $4.162 \times 10^{-8}$ & {$[23]$} \\
\hline $\mathrm{LiKB}_{4} \mathrm{O}_{7}$ & $4.85 \times 10^{-9}$ & {$[24]$} \\
\hline $\mathrm{DSHS}$ & $2.432 \times 10^{-7}$ & {$[25]$} \\
\hline $\mathrm{KDP}$ & $1.5 \times 10^{-14}$ & {$[26]$} \\
\hline
\end{tabular}

\section{CONCLUSION AND FUTURE SCOPE}

Single crystals of DKFD were grown from solvent evaporation method. The single crystal and powder XRD studies measures the lattice parameter of the grown crystal. The UV-Vis-NIR spectrum showed that the crystal has good transparency from 300 to $1100 \mathrm{~nm}$. The FTIR and FTRaman analyses confirms the presence of functional groups in the crystal. The NMR analysis finds the position of hydrogen and carbon atoms present in the structure of grown crystal. The thermal stability and decomposition temperature were investigated from TG/DTA experiments. From the z-scan measurement, the crystal exhibit negative nonlinear refractive index and self-defocussing effect. By growing a bulk crystal and further it can be used in optoelectronic applications.

\section{ACKNOWLEDGMENT}

The authors thank the Sophisticated Analytical Instruments Facility (SAIF), Indian Institute of Technology (IITM), Chennai for providing FT Raman spectrum and gratefully acknowledge the Instrumentation centre of St. Joseph's College, Trichy for recording UV-Vis-NIR spectrum. The authors wish to thank Madurai Kamaraj University, Madurai for single crystal XRD and FTIR studies, CECRI, Karaikudi, for powder XRD, NMR and TG/DTA studies. The authors are also grateful to Dr. G. Vinitha, VIT, Chennai for recording the $\mathrm{z}$-scan curves.

\section{REFERENCES}

[1] R. A. Laudise, 'The growth of single crystals', Prentice Hall, Eagle wood Cliffs New Jersy (1970).

[2] R. A. Laudise, R. Ueda, and J. B. Mullin (Eds.), 'Crystal growth and characterization', North-Holland publishing Co. (1975).

[3] A. David Kalaimani Raj, S. Chidambaram and R. Manimekalai, 'Growth and Investigation of L-Cysteine Doped Zinc (Tris) Thiourea Sulphate Single Crystals', Int. J. Sci. Res. in Physics and Applied Sciences, Vol.6(4), 2018.

[4] J. Wiliams (ed) Nonlinear optical properties organic and polymeric materials. American Chemical Society Symposium Series 233, American Chemical Society, Washington DC, (1983). [5] D. S. Chemla, and J. Zyss (eds) Nonlinear optical properties of organic molecule and crystals, vol 1 and 2. Academic press, New York, (1987).

[6] G. Xing, M. Jiang, Z. Shao, and D. Xu, Chin. J. Lasers, 14 (1987) 357-360.

[7] R. Mohan Kumar, D. Rajan Babu, D. Jayaraman, R. Jayavel, and K. Kitamura, 'Studies on the growth aspects of semi-organic L- 
alanine acetate: a promising NLO crystal', J Cryst Growth, 275 (2005) 1935-1939.

[8] L. F. Warren, Electronic materials-our future, in: R. E. Allred, R. J. Martinez, K. B. Wischmann (Eds.), 'Proceedings of the Fourth International Sample Electronics Conference', Society for the Advancement of Material and Process Engineering', Covina, CA, 4 (1990) 388.

[9] H. Q. Sun, D. R. Yuan, X. Q. Wang, X. F. Cheng, C. R. Gong, M. Zhou, H. Y. Xu ,X. C. We, C. N. Luan, D. Y. Pan, Z. F. Li and X. Z. Shi, 'A novel metal- organic coordination complex crystal: tri- allylthiourea zinc chloride (ATZC)', Cryst. Res. Technol., 40 (2005) 882-886.

[10] A. Arunkumar, P. Ramasamy, K. Vishnu, and K. Jayaraj, 'Growth, structural, thermal, optical, and electrical properties of potassium succinate-succinic acid crystal', J. Mater Sci., 49 (2014) 35983607.

[11] M. P. Gupta, and B. H. Sahu, 'The crystal structure of Dipotassium fumarate dihydrate', Acta Cryst., B26 (1970) 1969.

[12] B. Want, and M. D. Shah, 'Growth and characterization of terbium fumarate heptahydrate single crystals', J. Cryst. Growth, 389 (2014) 39-46.

[13] M. D. Shah and B. Want, 'Growth, characterization and dielectric studies of gadolinium fumarate heptahydrate single crystals', Bull. Mater. Sci., 38 (2015) 73-81.

[14] N. B. Colthup, L. H. Daly, and S. E. Wiberley, 'Introduction to infrared and raman spectroscopy', 2nd ed (NewYork,USA:AcademicPress)(1975).

[15] K. Nakamoto, 'Infrared and Raman spectra of inorganic and coordination compounds', 5th ed (New York: Wiley) (1997) 60.

[16] E. Y. Ionashiro, F. J. Caires, A. B. Siqueira, L. S. Lima and C. T. Carvalho, 'Thermal behaviour of fumaric acid, sodium fumarate and its compounds with light trivalent lanthanides in air atmosphere', J Therm Anal Calorim., 108 (2012) 1183-1188.

[17] P. Karuppasamy, V. Sivasubramani, M. Senthil Pandian, and P. Ramasamy, 'Growth and characterization of semi-organic third order nonlinear optical (NLO) potassium 3,5-dinitrobenzoate (KDNB) single crystals', RSC Adv., 6 (2016) 33159-33169.

[18] T. C. S. Girisun, S. Dhanuskodi and G. Vinitha, 'Measurement and optical limiting properties of metal complexes of thiourea using Z-scan', Mater. Chem. Phys., 129 (2011) 9-14,

[19] T. Thilak, M. B. Ahamed and G. Vinitha, Third order nonlinear optical properties of potassium dichromate single crystals by Z-scan technique, Opt. Int. J. Light Electron Opt.,124 (2013) 4716-4720.

[20] A. N. Vigneshwaran, P. Umarani and C. Ramachandra Raja, Studies on nonlinear optical ammonium pentaborate crystals, J. Mater. Sci. Mater. Electron. 28 (2017) 11430-11438.

[21] M. Sukumar, R. Ramesh Babu, and K. Ramamurthi, 'Linear and Third order nonlinear optical properties of $\mathrm{LiRbB} 4 \mathrm{O} 7$ single crystal', Solid state Sci., 51 (2016) 8-12.

[22] A. Subashini, R. Kumaravel, S. Leela, H. S. Evans, D. Sastikumar, and $\mathrm{K}$ Ramamurthi,

'Synthesis, Growth and Characterization of 4-Bromo-4' Chloro Benzylidene Aniline-A Third Order Non Linear Optical Material', Spectrochim. Acta Part A Mol. Biomol. Spectrosc. 78, (2011) 935-941.

[23] K. Sivakumar, Saravana Kumar, R. Mohan Kumara, R. Kanagadurai, and S. Sagadevan, 'Studies on Growth, Spectral, Thermal, Mechanical and Optical Properties of 4-Bromoanilinium 4-Methylbenzenesulfonate Crystal: A Third Order Nonlinear Optical Material', Materials Research , 19 (2016) 937-941.
[24] M. Sukumar, K. Ramamurthi and, R. Ramesh Babu, 'Linear and Third order nonlinear optical properties of LiKB4O7 single crystal', Applied Physics B, 121 (2015) 369-373.

[25] I. Md Zahid, S. Kalaiyarasi, S. Reena Devi, S. Suresh, T. Ganesh, and R. Mohan Kumar, 'Crystal growth, spectral, thermal, optical and third order nonlinearity studies of optical material: $4-\mathrm{N}, \mathrm{N}$ dimethylamino 4hydroxybenzenesulfonate', J. Opt., 46 (2017) 456-464.

[26] A. N. Vigneshwaran, P. Paramasivam, and C. Ramachandra Raja, 'A study on the linear and nonlinear optical properties of $\mathrm{Li}$ and $\mathrm{NH}_{4}$ doped potassium pentaborate crystals', Mater Lett., 178 (2016) 100-103

\section{AUTHORS PROFILE}

Mr. N. Kalaimani pursed Bachelor of Science, Master of Science and M.Phil., in TBML College, Porayar,, Tamil Nadu, India and Bharathidasan University, Tiruchirappalli. He is currently pursuing his Ph.D degree in part-time as a part- time in Government Arts College (Autonomous), Kumbakonam-612 002 (affiliated to Bharathidasan University) and currently working as an Assistant professor of Physics, Thiru.Vi.Ka Government Arts College, Thiruvarur 610 003, Tamil Nadu, India. His main research work focuses on crystal growth and characterization. He has 23 years of teaching and research experience in UG and PG level.

Dr.K.Ramya has completed her Ph.D degree in the year 2017 from Government Arts College (Autonomous), Kumbakonam affiliated to Bharathidasan University, Tiruchirappalli. she has published more than 5 papers in international peer reviewed journal and attended 2 international conferences. Presently she is working as an Assistant professor of Physics, TUK Arts College, Thanjavur 613 002, Tamilnadu, India. Her main research work focuses on crystal growth and characterization in liquid diffusion method. she has 9 years of teaching and research experience in UG level.

Ms.Aarthi.R has completed her M.Sc and M.phil from St.Joseph's College (Autonomous), Thiruchirappalli affiliated to Bharathidasan University, Tiruchirappalli. She has published more than 7 papers in international peer reviewed journal and attended 6 international conferences. Presently she is doing her full-time research in Government Arts College (Autonomous), Kumbakonam 612 002, Tamilnadu, India. Her main research work focuses on crystal growth and characterization through solvent evaporation solution growth method. She has found 4 new crystal structures and reported in IUCR data reports.

Dr. Ramachandra Raja.C has completed his Ph.D degree in the year 1994 from Anna University, Chennai. Presently he is working as an Associate professor of Physics, Government Arts College(Autonomous), Kumbakonam-612 002, Tamil Nadu, India. Having 22 years of teaching and research experience in UG, PG and M.Phil., level. His field of interest is crystal growth and characterization, magnetic materials and Biomaterials. Acting as research advisor from the year 2007 and 11 students have got their $\mathrm{Ph} . \mathrm{D}$ degree under his guidance. So for he has found 11 new crystal structures and the structures were reported in IUCR data reports. He has published more than 90 research papers in reputed, peer reviewed, science citation indexed journals (Elsevier, Springer, etc.,) and delivered more than 18 invited talk in various international conferences. At present he is guiding 8 Ph.D scholars. 